\title{
Resumos de Teses
}

Hiperintensidades da substância branca à ressonância magnética na doença de Alzheimer e no envelhecimento normal.

Autora: Zélia Maria de Sousa Campos. Orientador: Giovanni Guido Cerri. Tese de Doutorado. USP, 2001.

O objetivo deste trabalho foi empregar uma escala de análise visual de hiperintensidades encefálicas em T2, volume do sistema ventricular e volume do espaço subaracnóide em exames de ressonância magnética em 16 indivíduos idosos normais, 19 com transtorno cognitivo leve (TCL) e 36 com doença de Alzheimer (DA). Foram estabelecidos vários parâmetros (variáveis) para o estudo dos itens acima, e a escala foi empregada com sucesso.

0 grupo de pacientes com TCL apresentou menores escores de hiperintensidades periventriculares frontais que o grupo de pacientes com DA. 0 grupo controle apresentou escores de hiperintensidades em faixa periventriculares significativamente menores que os do grupo DA e TCL. No parâmetro hiperintensidades periventriculares (totais), o grupo controle apresentou valores significativamente menores que os dos grupos DA e TCL. Na variável hiperintensidades da substância branca temporal, o grupo DA apresentou valores significativamente maiores que os dos outros grupos. Os grupos diferiram entre si quanto às variáveis hiperintensidades da substância branca supratentorial, supratentoriais, totais e da substância branca total, sendo que o grupo TCL apresentou valores significativamente menores que os do grupo DA. Os grupos não diferiram entre si nos parâmetros de hiperintensidades de núcleos da base, tálamos e cápsula interna (considerados no total) e hiperintensidades infratentoriais. Observou-se que os grupos diferiram entre si quanto ao volume dos ventrículos, exceto quanto ao quarto ventrículo. Quanto aos ventrículos laterais, terceiro ventrículo, ventrículos supratentoriais e ventrículos totais, o grupo controle apresentou valores significativamente menores que os do grupo DA.

Os grupos diferiram entre si no que se refere ao espaço subaracnóide. 0 grupo controle apresentou valores de espaço subaracnóide frontal, temporal, parieto-occipital, infratentorial, supratentorial e total significativamente menores que os do grupo DA $(p<0,05)$. Observou-se ainda que os grupos diferiram entre si nos parâmetros do líquido cefalorraquiano avaliado globalmente, exceto quanto ao parâmetro líquido cefalorraquiano total infratentorial. O grupo controle apresentou valores de líquido cefalorraquiano total supratentorial e líquido cefalorraquiano total significativamente menores que os do grupo DA.

Quando da casuística foram excluídos sujeitos com risco para doença cerebrovascular, a maior parte das análises anteriores apresentou resultados semelhantes. A análise de regressão logística identificou a variável espaço subaracnóide temporal (ES-TE) como a melhor para diagnóstico de pacientes com DA, quando comparados aos controles, com uma sensibilidade de $80,6 \%$ e especificidade de $68,8 \%$.

Radioterapia exclusiva no tratamento do câncer do colo do útero com telecobalto $e$ braquiterapia de baixa taxa de dose: análise de resultados e variáveis.

Autor: Robson Ferrigno.

Orientador: Wladimir Nadalin. Tese de Doutorado. USP, 2001.

A presente série reporta os resultados de uma análise retrospectiva de pacientes portadoras de câncer do colo do útero, tratadas com radioterapia exclusiva,através de telecobalto e braquiterapia de baixa taxa de dose.

De setembro de 1989 a setembro de 1995, 190 pacientes com diagnóstico histológico de carcinoma epidermóide do colo do útero foram tratadas com radioterapia externa em um equipamento de telecobalto, tendo sido planejados quatro campos e tratados dois por dia, em forma de rodízio, seguida de uma ou duas inserções de braquiterapia de baixa taxa de dose (BBTD). A idade das pacientes variou de 24 a 77 anos (mediana de 53 anos) e o peso variou de 41 a $89 \mathrm{~kg}$ (mediana de $60 \mathrm{~kg}$ ). Dessas, 12 eram estádio clínico (EC) IB, quatro eram EC IIA, 105 eram EC IIB e 69 eram EC IIIB.

A dose mediana de radioterapia externa na pelve de todas as pacientes foi de 4.000 cGy; as doses medianas em campos de paramétrios das pacientes EC I, EC II e EC III foram de 4.000 cGy, 5.000 cGy e 6.000 cGy, respectivamente, e as doses medianas de braquiterapia no ponto $A$ das pacientes tratadas com uma BBTD e com duas BBTD foram de 3.800 cGy e 5.000 cGy, respectivamente. 0 período de seguimento variou de oito a 127 meses (mediana de 70 meses).

Com relação às pacientes EC I, II e III, a sobrevida global em cinco anos foi de $83 \%, 78 \%$ e $46 \%$, a sobrevida livre de doenças foi de $83 \%$, $82 \%$ e $49 \%$, e o controle local em cinco anos foi de $92 \%, 87 \%$ e $58 \%$, respectivamente. As complicações crônicas no reto, no intestino delgado e nas vias urinárias, independentemente da graduação, foram observadas em 29 $(15,3 \%)$, em oito $(4,2 \%)$ e em $13(6,8 \%)$ pacientes, respectivamente. Fibrose subcutânea foi observada em oito pacientes $(4,2 \%)$ e estenose vaginal em 61 pacientes $(32,1 \%)$.

A análise estatística revelou o EC como a única variável significativa para a sobrevida global $(p=0,000)$, para a sobrevida livre de doença $(p=0,000)$ e para o controle local $(p=$ 0,000 ). Idade maior que 50 anos foi a única variável que aumentou o controle local e a sobrevida livre de doença das pacientes EC II ( $p$ $=0,004)$. Tempo de tratamento superior a 60 dias foi a única variável que aumentou o índice de complicações no reto em cinco anos ( $p=$ 0,022 ). Idade até 50 anos foi a única variável que aumentou significativamente a incidência de complicações nas vias urinárias em cinco anos $(p=0,011)$.

Os resultados de sobrevida global, de controle local e de complicações crônicas das pacientes da presente série foram semelhantes aos das principais séries da literatura. Esses resultados sugerem que o uso de equipamento de telecobalto e a estratégia de planejar quatro campos e tratar dois por dia em forma de rodízio, até dose de 5.000 cGy na pelve, previamente à braquiterapia, representa uma técnica aceitável de radioterapia exclusiva no tratamento de pacientes com câncer do colo do útero e com peso até de $89 \mathrm{~kg}$, principalmente em países em desenvolvimento e com demanda reprimida, como o Brasil. 